\title{
Uma Análise Crítica Sobre Amor e Cuidado em Binswanger e Heidegger
}

\author{
Ana Maria Lopez Calvo de Feijoo* \\ Universidade do Estado do Rio de Janeiro - UERJ, Rio de Janeiro, RJ, Brasil \\ ORCID: http://orcid.org/0000-0002-3064-3635 \\ Marcello Furst de Freitas Accetta** \\ Centro Universitário Augusto Motta - Unisuam, Rio de Janeiro, RJ, Brasil \\ ORCID: https://orcid.org/0000-0001-5976-0352 \\ Myriam Moreira Protasio*** \\ Instituto de Psicologia Fenomenológico-Existencial do Rio de Janeiro - IFEN, Rio de Janeiro, RJ, Brasil \\ ORCID: https://orcid.org/0000-0002-2156-9269 \\ Paulo Victor Rodrigues da Costa***** \\ Universidade do Estado do Rio de Janeiro - UERJ, Rio de Janeiro, RJ, Brasil \\ ORCID: https://orcid.org/0000-0002-4883-0295 \\ Victor Portavales Silva***** \\ Universidade do Estado do Rio de Janeiro - UERJ, Rio de Janeiro, RJ, Brasil \\ ORCID: https://orcid.org/0000-0001-6747-0451
}

\section{RESUMO}

O presente artigo tem como objetivo refletir, por meio de um estudo teórico, acerca do existencial cuidado (Sorge) no pensamento de Martin Heidegger e amor (Liebe) em Ludwig Binswanger. $\mathrm{O}$ texto retoma os principais aspectos da forma como ambos compreendem a noção de cuidado e amor, desdobrando criticamente o impasse gerado a partir daí. Demonstrase que o cerne da querela se dá no modo como Binswanger compreende e interpreta o ser-nomundo (In-der-Welt-sein) heideggeriano, ligando-o à noção de ser-para-além-do-mundo (Über-die-Welt-hinaus-sein). O psiquiatra suíço procede desse modo na medida em que julga ter identificado um limite e uma carência do elemento eternidade no modo como Heidegger desenvolve sua ontologia fundamental. Com tal apontamento, Binswanger elege a tonalidade do amor como fundamento de toda relação, que faz dessa experiência de infinito sua forma de ser. No bojo de tal apontamento se encontra o desenvolvimento da Daseinsanálise como o desdobramento - a princípio psiquiátrico - de uma relação clínica pautada pelo amor como meio do acesso fundamental ao outro e como elemento que promove a cura. $\mathrm{O}$ artigo conclui que tal indicação binswangeriana recai sutilmente em elementos instrumentais e produtivistas, uma vez que Binswanger reproduz elementos da técnica justamente lá onde tais elementos deveriam permanecer inoperantes.

Palavras-chave: Martin Heidegger, Ludwig Binswanger, daseinsanálise, amor, cuidado.

\section{A Critical Analysis of Love and Care in Binswanger and Heidegger}

\section{ABSTRACT}

This article is a theoretical study to reflect on the existential care (Sorge) in Martin Heidegger and the love (Liebe) in Ludwig Binswanger. The text retakes the main aspects the way both understand care and love, unfolding in a critical way the impasse caused from there. It is 
demonstrated that the center of the discussion is the way Binswanger understands and interprets the Heideggerian being-in-the-world (In-der-Welt-sein), linking it to the notion of being beyond the world (Über-die-Welt-hinaus-sein). Binswanger identifies a limit and a flaw in the element of eternity in the way Heidegger develops his fundamental ontology. By this he points out to the experience of love as the basis of each relationship, making this experience of the infinite as the way of being of love and the basis of all relationships. In the center of such consideration is the development of Daseinsanalysis as the unfolding - at first psychiatric - of a clinical relationship guided by love as a means of fundamental access to the other and as an element that promotes healing. It is concluded that the Binswangerian indication subtly falls on the productivism and instrumental elements, since Binswanger reproduces elements of technology exactly where those elements must remain inoperative.

Keywords: Martin Heidegger, Ludwig Binswanger, daseinsanalysis, love, care.

\section{Un Análisis Crítico sobre Amor y Cuidado en Binswanger y Heidegger}

\section{RESUMEN}

El objetivo de este artículo es reflejar teóricamente sobre el existencial cuidado (Sorge) en los estudios de Martin Heidegger y amor (Liebe) en Ludwig Binswanger. El texto retoma los principales aspectos de cómo ambos entienden esas nociones, para desplegar críticamente el impasse generado a partir de ahí. El núcleo de la disputa tiene lugar en la forma en que Binswanger entiende e interpreta el ser-en-el mundo (In-der-Welt-sein) heideggeriano, vinculándolo a la noción de estar más-allá-del-mundo (Über-die-Welt-hinaus-sein). El psiquiatra lo hace cuando considera identificar un límite y una falta de eternidad en la forma en que Heidegger desarrolla su pensamiento. Con tal nota, Binswanger elige el tono del amor como la base de cada relación, que hace de esta experiencia del infinito su forma de ser. En el abultamiento de esta nota está el desarrollo de la Daseinsanalysis como un desdoblarse del inicio psiquiátrico - de una relación clínica guiada por el amor como el acceso fundamental del otro y aún como aquello que conduce a la cura. El artículo concluye que aquello lo que indica Binswanger se queda sutilmente en elementos instrumentales y productivistas, pues Binswanger reproduce elementos de la técnica donde tales elementos deberían mantenerse inoperantes.

Palabras clave: Martin Heidegger, Ludwig Binswanger, daseinsanalysis, amor, cuidado.

O impasse entre Binswanger e Heidegger se instaurou pelo fato de ambos discordarem acerca da diferente compreensão com que cada um apreendeu o sentido do existencial cuidado (Sorge). Além disso, ambos mantêm um desacordo com relação à noção de ser-no-mundo (Inder-Welt-sein). Binswanger (1942/1964), em Grundformen und Erkenntnis menschlichen Daseins (Formas fundamentais e conhecimento da existência humana), se propõe a revisar o caráter finito da ontologia fundamental de Heidegger, contido no existencial ser-para-a-morte, 
e acrescenta a ideia de transcendência, utilizando o termo ser-para-além-do-mundo (Überdie-Welt-hinaus-sein). Com isso, o psiquiatra acredita ter trazido um elemento transcendente ao ser-no-mundo heideggeriano. Heidegger (2009b/1928), por sua vez, diz que a compreensão de Binswanger sobre o Dasein está equivocada, porque despreza o caráter original do Dasein, que é compreensão de ser, e o torna antropológico a partir da redução a alguns momentos estruturais, como o aí e o ser-para-a-morte.

Sem dúvida, esse impasse entrou para a história da daseinsanálise. Trata-se de uma questão muito discutida por estudiosos do tema, de modo que os diferentes desacordos entre o filósofo e o psiquiatra conduziram a posicionamentos divergentes por parte dos pesquisadores da daseinsanálise. Vale ressaltar que o próprio Binswanger (1964), mediante as críticas do filósofo, recua no seu posicionamento e consente que se equivocou. No entanto, ele defende que foi um equívoco produtivo uma vez que, por meio desse equívoco, pôde construir o que ele mesmo denominou de fenomenologia antropológica. Na edificação de sua fenomenologia antropológica, o psiquiatra retoma a fenomenologia de Husserl, centrando-se em uma fenomenologia na qual importa a gênese da subjetividade, passando a investigar a constituição dos mundos da melancolia, da mania e da esquizofrenia. É compreensível que estudos sobre patologias mentais tenham se desenvolvido a partir dessa proposta.

Se por um lado a psiquiatria do século passado valorizou tais desdobramentos, por outro há estudiosos de Heidegger, como por exemplo Loparic (2002), que concordam com a crítica de Heidegger a Binswanger. Os que tomam essa posição concluem que a transposição da filosofia para a psiquiatria foi totalmente improdutiva, ou melhor, um contra serviço às elaborações em psiquiatria, bem como um ultraje às considerações filosóficas. Loparic afirma e reafirma que o existencial cuidado foi mal compreendido por Binswanger (1964), ao apontar para a insuficiência do existencial Sorge (cuidado) e ao considerar que o ser-no-mundo não contempla o caráter eterno do existir. Binswanger conclui que é o amor que está na base de toda e qualquer relação.

Por outro lado, há os que consideram que a crítica de Heidegger com relação ao modo como o psiquiatra posiciona o existencial Sorge, ou seja, substituindo-o pelo amor, foi extremamente radical e que a proposta de Binswanger foi mal compreendida pelo filósofo. Stein (2012) valoriza o psiquiatra por sua criatividade em incorporar aos seus estudos sobre as doenças mentais posições filosóficas tanto de Heidegger quanto de Husserl. E, ainda, avalia que entre Binswanger e Heidegger houve encontros e desencontros, mas que a maior dificuldade de Heidegger foi não ter levado em consideração a mediação antropológica necessária para atravessar a fronteira ente a filosofia e a psiquiatria. Stein (2012) finaliza 
dizendo: "Sem essa mediação, a discussão pode ser levada para qualquer direção, menos para a possibilidade de um verdadeiro encontro produtivo" (p. 121).

Há ainda aqueles que argumentam no sentido de encontrar uma reconciliação entre o pensamento de Heidegger sobre $o$ Sorge e a base da relação amorosa em toda e qualquer relação proposta por Binswanger. Esses argumentos podem ser encontrados em Irene Borges Duarte (2019) que admite a incompreensão do psiquiatra sobre o existencial cuidado. Por outro lado, essa estudiosa defende que a tese do psiquiatra, com seu equívoco, alcançou uma dimensão específica do cuidado que expressa o ser-a-dois, ou seja, o ser-aí como nostridade.

Com o objetivo de promover mais esclarecimentos acerca da proposta de Binswanger e de Heidegger, trilhamos o caminho de estudos pormenorizados dos textos em que cada um desses autores discutem o tema do cuidado e do amor. Assim, em Binswanger estudamos a obra Grundformen und Erkenntnis menschlichen Daseins e suas considerações sobre o amor. Em Ser e tempo tomamos o que Heidegger nos diz sobre o existencial cuidado (Sorge). Uma vez esclarecido o modo como ambos autores tratam esses fenômenos, trazemos os impasses entre esses dois estudiosos. De posse dessas considerações e suas consequentes análises, alcançamos nossas conclusões sobre o modo como Heidegger e Binswanger tratam, respectivamente, dos temas cuidado e amor. Dessa forma, o nosso estudo contribui com mais uma análise crítica acerca da produtividade ou improdutividade da transposição efetuada pelo psiquiatra.

\section{A Relação de Amor na Daseinsanálise de Binswanger}

Durante a sua fase baseada na fenomenologia heideggeriana. Binswanger publica, em 1942, a primeira edição de sua obra fundamental: Grundformen und Erkenntnis menschlichen Daseins. Machado (2019) afirma que durante toda a sua trajetória de pensamento Binswanger tem como marca central a defesa de uma proximidade incomparável entre o paciente e o seu mundo, e é baseada nessa relação de proximidade que esse trabalho se destaca em sua produção. Para além dessa defesa proposta por Machado (2019), as Grundformen se destacam por serem o marco onde Binswanger arrisca a implosão do conceito heideggeriano de mundo. Hertz (2013) nos diz que, para além de Heidegger, esse livro desenvolve a ontologia do ser em direção a uma ontologia social; e o próprio Binswanger (1964) declara que a obra contém os princípios para uma fenomenologia da situação psicoterapêutica em geral tanto quanto da concreta. 
Binswanger (1964) questiona, junto a Heidegger, a concepção de que a espacialidade do ser em relação a outro é compreendida de uma forma objetal - ou como um ser simplesmente dado - como uma coisa ao lado da outra e, consequentemente, uma coisa pode ocupar o lugar da outra. Assim, em sua compreensão, promover alterações, correções ou cura fazem parte de uma ação que, no espaço compartilhado, ocorre através da superação de alguma resistência. Diz Binswanger (1964): “Aqui temos uma arrumação do espaço do um ao outro que é um e, por isso, indivisível; espaço do infinito, inesgotável e insondável nós do amor” (p. 26). Para confrontar as formas de cuidado heideggerianas de preocupação e ocupação, Binswanger (1964) descreve um modo do cuidado enquanto ocupação para além dos limites corpóreos - significa conceder o lugar num contexto significativo (desta posição renuncio e me afasto) - onde um entrega ao outro seu espaço e o outro recebe a entrega. Um renuncia e se afasta, enquanto o outro assume o lugar. Desta forma, o médico inicia sua investigação do ser com o outro que ama - ou o amor - a partir da espacialidade. Para Binswanger o amor se distingue da ocupação na maneira como se configura o espaço próprio, por não exercer violência, pressão ou uso de poder para vencer ou suprimir resistências. No amor não há crescimento ou diminuição do espaço próprio, pois não há um ceder ou recuar o lugar, há uma arrumação do espaço que é visto como indivisível, "do um ao outro, que é um.". (Binswanger, 1964, p. $26^{1}$ )

Binswanger (1964) recorre à poesia e à literatura para justificar que a linguagem do amor permite que tratemos o amor como se dando numa compreensão de espacialidade infinita, sem fronteiras, onde os amantes não limitam o espaço um do outro, mas sim promovem uma constante criação mútua de espaço de liberdade um para o outro que se apresenta como um espaço de proximidade e familiaridade. O psiquiatra descreve a estrutura espacial do um com o outro que ama da seguinte forma:

[...] Apenas porque "no" nós, eu e tu já somos - enquanto pertencentes um ao outro -, pertenço eu àquele lugar onde tu estás, consigo estar aí onde tu estás, consigo "fazer surgir" aí onde tu estás um lugar "para mim”, consigo dispor teu vir-a-estar-aí, teu estar-aí (e ter-estado-aí) sobre o meu aqui. A “orientação fática” no sentido do aqui e aí só é possível aqui em razão da arrumação que ama, da arrumação de espaço de um ao outro ou da nostridade que ama. Mas isso não quer dizer que aqui duas existências projetam numa intencionalidade a cada vez unilateralmente constitutiva cada - cada seu - mundo e tomam parte em seus mundos mútuos, mas que o Dasein 
originalmente, isto é, sem o "desvio" pelo mundo ou si mesmo, arruma espaço para o aí do um-com-o-outro." (Binswanger, 1964, pp. 29)

Binswanger constrói, assim, o seu conceito de nostridade - fundado no caráter de abertura constitutivo do Dasein já incluindo um nós que permite compartilhar mundo - onde a espacialidade da maneira como ele compreende como amor é o que permite a diferenciação dos seres intramundanos.

Seguindo sua proposta de investigação do amor, Binswanger (1964) define a temporalidade a partir de uma co-pertença de um ao outro que não resulta numa queda no modo inautêntico das relações de ocupação estabelecidas cotidianamente. A temporalidade do amor retorna em um movimento eterno que devolve ao Dasein seu caráter de poder ser no nós. A eternidade aqui é marcada, por uma demonstração que, segundo Binswanger:

[...] do fenômeno essencialmente pertencente à existência fenomenal do amor, à sua estrutura de ser, fenômeno, aliás, do de volta temporal do presente ao passado e do adiante para o porvir, dessa insuficiência essencial no presente e ser dependente do passado e do futuro". (Binswanger, 1964, pp. 41)

Desta forma Binswanger (1964) define a temporalidade do amor como "transitoriedade da vida, isto é, tornar-se e transcorrer" (p. 43), como "duração eterna" que atualiza e devolve ao ser um com o outro que ama o instante.

A espacialidade se configura assim na temporalidade infinita do amor. Na relação de um que ama com outro que ama se faz morada um no outro, e desta forma a espacialidade surge independentemente dos distanciamentos físicos. O espaço, no amor, se perde para além das fronteiras, na infinitude, assim como no eterno do tempo. O Dasein no amor se atualiza no instante e contrapõe a decadência - passando a estar mais autenticamente na situação, tomado pela decisão no sentido de se manter livre para o poder-ser. Para Binswanger o amor se diferencia do projeto de ser do Dasein na autenticidade, isso porque como o poder-ser se compreende a partir da finitude do Dasein, da decisão que pode sempre se saber, o amor não se estabelece na compreensão de ser para a morte nem no poder-ser autêntico que se dá na decisão. Para o psiquiatra o amor:

(...) não nega, assim, a morte, na verdade, dá-se o contrário. Ele não lhe retira o sentido verdadeiro, a certeza do tomar-por-verdadeiro de seu ser; pois ele apenas é na 
medida em que, conscientes da certeza da morte, não nos angustiemos diante dela, não nos sintamos em débito, acima de tudo não nos curvemos, e sim, nos mantenhamos livres, mas não no sentido da nadidade do Dasein, de seu fim, quando sim de sua duração “eterna”. (Binswanger, 1964, pp. 52)

Desta forma, Binswanger (1964) afirma que o amor não pode ser compreendido a partir da finitude, da temporalidade do Dasein, mas sim da infinitude. A temporalização do amor, mesmo que ameaçado pela finitude, se dá na situação, na atualidade, e também no passado e no futuro. Sendo assim, o amor para os que amam não se pode posicionar na cotidianidade como um ser simplesmente dado, como algo no sentido do mundo manual, o que é descrito pelo psiquiatra como um a cada vez - a cada vez num modo de estarem um com o outro. Segundo ele, nesse modo:

[...] são, para o já-ser no modo do 'vigor de ter sido' - mas não ao mim, ao Dasein enquanto meu, mas - ao um ao outro, e eles não são a cada vez o si mesmo à frente no deixar-se-vir-a-cada-vez-a-si do futuro, mas são o um à frente do outro no deixar-seaproximar um do outro do futuro. (Binswanger, 1964, pp 57)

A atualização que se dá na situação do amor se situa, assim, para além da decisão entre a autenticidade e o impessoal, e além da temporalização da finitude; se dá na espacialidade que se dá um para o outro - sem reivindicar ou entregar - na morada, na nostridade. Assim, para Binswanger, o caráter de poder-ser sempre e a cada vez do Dasein passa a ser compreendido para aquele que ama o "sempre e a cada vez nosso" (Binswanger, 1964, p. 59), entendendo a relação com esse caráter como anterior ao caráter singular e de isolamento do Dasein em si mesmo.

Binswanger (1964) tem conhecimento que o ser-no-mundo é definido por Heidegger como parte estruturante do Dasein, assim como os modos de encontro no mundo ao modo do ser-com, ou ser-junto-a. Mas, para o psiquiatra, é exatamente a constituição de ser-no-mundo que define a espacialidade do Dasein, e não o contrário, dada a sua corporalidade mediada pela corporeidade. Tal reflexão advém do fato do ser-no-mundo ser enquanto ocupação, tomado pela ocupação e tomando-se como ente intramundano. O encontro do Dasein, ou o dirigir-se para, no mundo, não se dá através de uma perspectiva internalista, pois o Dasein é sempre fora, junto aos entes que lhe veem ao encontro no mundo. 
Binswanger (1964) busca, assim, diferenciar a mundanidade constitutiva na estrutura do ser-no-mundo enquanto um existencial proposto por Heidegger a partir de um posicionamento da relação ôntica estabelecida pelo Dasein no mundo fático, no mundo em que se vive, do nós-mundo no sentido do amor. O psiquiatra descreve que a mundanidade se apresenta para o Dasein como um contexto referencial onde o Dasein se compreende e compreende, na totalidade conjuntural, a manualidade das coisas intramundanas no mundo circundante. O mundo circundante é descrito pelo médico como o que se refere à espacialidade no sentido do contexto referencial, que retoma dois pontos para tratar dos modos de abertura do ser-no-mundo:

sendo o primeiro a disposição afetiva [Befindlichkeit] ou "humor” [Stimmung], à qual fundamental-ontologicamente devemos deixar a descoberta primária do mundo; e o segundo a compreensão. A compreensão está, de fato, sempre em um humor; ela diz respeito, porém, em contraposição ao "mero" humor, enquanto "abrir" e "projeto", isto é, enquanto poder ser conseguido pela possibilidade, sempre à constituição fundamental do ser-no-mundo; ela pode ser uma compreensão autêntica que surge de seu próprio si mesmo enquanto tal, ou uma inautêntica, isto é, uma tal que se compreende a partir de seu mundo. (Binswanger, 1964, pp. 65)

A partir desta explicação, Binswanger define o modo de ser-no-mundo como constituído em momentos diferentes, sendo a mundanidade apenas um deles. Para ele, o sercom é um segundo momento; e o terceiro é definido pela decisão do quem do Dasein enquanto ser-no-mundo como autêntico e inautêntico. Desta forma, ele denuncia que não se encontra na obra Ser e tempo de Heidegger nenhuma menção ao ser-quem do Dasein na nostridade, ou seja, a relação de um com outro, do eu com o tu, ficaria sem ser esclarecida. Para Binswanger (1964) о eu sou do Dasein, anunciado por Heidegger, suprime o tu és cooriginário no modo do ser-com no mundo compartilhado, o que não é possível ao tratar do amor. Como sempre vêm ao encontro do Dasein todos os outros no mundo circundante, e todos os referenciais de contexto das coisas manuais para os outros é sempre também esse mundo que é já o meu. O estar-aí dos outros não pode ser tomado a partir de um caráter simplesmente dado, mas sim a partir de uma "igualdade do ser enquanto ser-no-mundo circunvisivo-ocupante" (Binswanger, 1964, p. 67), pois mundo é sempre mundo compartilhado com os outros. Para Binswanger, o Dasein não pode se apropriar do ser-com 
ao modo da ocupação, pois o ente com o qual se relaciona apresenta a mesma estrutura fundante como ele mesmo. Em suas palavras:

Aqui o que nos interessa acima de tudo é que o Dasein enquanto ser-com não está em função de seu próprio ser, mas em função dos outros. No ser-com "enquanto no em função dos outros existencial" - com o qual ele "não pode ter nenhuma conjuntura", assim como com o ser do Dasein para com seu mais autêntico ser - isso pois, os outros não são manuais, nem instrumentos - no ser-com os outros já estão "abertos" em seu Dasein. (Binswanger, 1964, pp. 67)

\section{A Noção de Cuidado (Sorge) em Ser e Tempo}

Para compreendermos à noção de cuidado (Sorge) em Heidegger (1927/1988) é necessário deter-nos na tarefa específica que esse termo possui em Ser e tempo. É assim na medida em que o texto citado é o lugar onde tal noção ganha proeminência dentro de seu caminho de pensamento ${ }^{2}$. No texto de 1927 , Heidegger identifica a necessidade de retomar a pergunta ontológica como pergunta fundamental do filosofar. O ponto é que essa pretensão de Ser e tempo organiza a obra em torno de três eixos fundamentais: em primeiro lugar, a questão-chave de uma ontologia fundamental traz à baila a necessidade de questionamento (destruição) da história da ontologia tradicional, isto é, uma reconsideração do modo como a tradição desse questionamento se calcificou e perdeu seu solo originário; em segundo lugar, a indicação de como essa questão se relaciona com a existência em sua facticidade, isto é, Heidegger (1927/1988) tenta vincular a questão ontológica ao como da vida cotidiana, advertindo que nessa vida cotidiana reside a própria ligação com a questão ontológica a ser desdobrada, a chamada hermenêutica da facticidade; uma terceira é a necessidade desse questionamento se dar, portanto, através do que chama de uma analítica existencial. É somente por meio da analítica do Dasein em sua hermenêutica concreta que se pode atingir a questão ontológica que norteia Ser e tempo. Essas três características - analítica existencial, hermenêutica da facticidade e destruição da ontologia tradicional - trabalham juntas e não podem ser compreendidas umas sem as outras. O ponto de partida para o projeto de Ser $e$ tempo se dá por meio da descrição fenomenológica das estruturas ontológicas do ser-aí. Com a finalidade de responder à pergunta pelo sentido de ser, Heidegger inaugura uma investigação minuciosa do modo de ser do único ente capaz de se colocar tal pergunta: o Dasein. 
Já que a finalidade é a destruição da história da ontologia e a necessidade de vincular tal destruição com a facticidade da existência, nada mais elementar do que iniciar tal trajetória centralizando-se na analítica existencial do Dasein. O ponto é que essa analítica necessita de uma precisa descrição fenomenológica dos momentos que constituem o modo de ser do Dasein. É somente por meio dessa descrição fenomenológica dos momentos que compõem o Dasein que o objetivo final de uma ontologia fundamental é possível. A expressão descrição dos momentos fenomenológicos remonta a Husserl (1901/2007) quando este se volta para a descrição dos elementos que compõem um determinado ente. Para compreender o sentido dessa expressão precisamos visualizar a diferença entre pedaço e momento no interior da fenomenologia husserliana. Um pedaço é um elemento destacado do todo de um objeto e que, mesmo destacado, possui existência independente. Por exemplo, podemos retirar o fruto de uma árvore, esse fruto destacado analisado isoladamente possui identidade própria, configurando por meio daí que o fruto é um pedaço da árvore. Por sua vez, o momento é parte de algo que não pode ser desvinculado e destacado dele, pois não se sustenta de forma independente. Nesse caso podemos pensar na própria cor do fruto. A cor não tem possibilidade de ser analisada de forma desconexa da superfície mesma do fruto, como se fosse uma cor que se desse sem uma superfície espacial que a delimita. Nesse caso, a cor é um momento do fruto já que ela não pode ser considerada isoladamente e só ganha sua viabilidade quando inserida numa relação com o todo do fruto. Da mesma forma, o que Heidegger faz é se utilizar desse modelo descritivo husserliano para indicar o Dasein em seus diversos momentos - e não pedaços - constituintes. Isso quer dizer que a partir da clarificação dos momentos que compõem o ser-aí é possível a paulatina conquista do próprio como fático do seu existir e dos sentidos e significados em jogo no cotidiano, bem como a relação disso com o solo da questão do sentido do ser. Sem essa descrição dos momentos - na linguagem de Ser e tempo, estruturas ontológicas - que compõem a existência é como se não houvesse caminho possível para o empenho heideggeriano: somente por ele [Dasein] que essa investigação pode e deve começar.

O ponto é que a exigência de clarificação dos momentos que compõem o Dasein determina que se delimite toda uma série conexa de elementos que estruturam a escrita de Ser e tempo, desdobrando uma espécie de coluna de sustentação do texto que possa de fato levar da descrição dos momentos fenomenológicos do Dasein à questão fundamental do sentido do ser. O primeiro desses elementos diz respeito ao fato de o Dasein se dar como ser-no-mundo, isto é, como abertura relacional. Essa abertura é o que essencialmente o caracteriza enquanto tal. Por meio da abertura de mundo, que o Dasein é, abrem-se co-originariamente os 
chamados entes intramundanos que vêm ao encontro por meio dessa abertura mesma e exigem do Dasein uma lida correspondente com eles. Esse ter de lidar com os entes por meio da abertura relacional que se é traz à tona aquilo que Heidegger chama de cuidado (Sorge). O Dasein tem de lidar com a abertura relacional que ele mesmo é. O fato de a existência humana ser cuidado não significa, para Heidegger, que ela possui uma postura ontologicamente amistosa e amável com os entes em geral, com outros seres-aí e consigo mesma. Na verdade, tem a ver com o vínculo do Dasein com a noção de sentido e de tempo.

Na medida em que somos seres compreensivos - não no sentido de ter empatia amistosa com o outro, mas por já sempre nos relacionarmos aberta e claramente com aquilo com o que nos relacionamos -, sempre nos colocamos em relação de finalidade com as nossas ações e com os diversos campos de nossa existência. Existir significa, mesmo que não saibamos disso cognitivamente, colocar-nos em meio a relações de finalidade. Por exemplo: acordar cedo durante a semana significa a interrupção do sono para que determinada tarefa tenha lugar, tarefa essa que se sobrepõe ao sentido de continuar dormindo. O desempenho de determinada tarefa, seja ela qual for, diz respeito a uma relação com aquilo que é feito e sua importância. Pode-se ter como exemplo situações corriqueiras como fazer exercício, trabalhar, ter aula, ir ao cinema etc. O ponto é que as nossas ações - mesmo que desapercebidamente indicam justamente a relação de sentido com aquilo que é feito. Faz sentido acordar e não continuar dormindo para que determinada tarefa existencial seja cumprida. Aquilo que permite uma sobreposição do acordar frente ao dormir indica uma relação de sentido e uma questão existencial aí em jogo. O existir humano se vê mobilizado na direção de determinada ação pois faz sentido agir desse e não de qualquer outro modo. Tal simples descrição cotidiana revela algo mais fundamental: a necessidade da nossa existência precisar de sentido para ser. Temos de lidar com nossa existência mesma a todo instante. Por isso falar na estrutura do cuidado traz à tona a questão do sentido, pois cuidado implica a facticidade do existir e as ações cotidianas.

Enquanto existente o Dasein sempre se dará, de maneira inalienável, ao modo do cuidado. Por sua vez, aquilo que se revela com o fato de o Dasein ser incessantemente ao modo do cuidado - mesmo distraído para isso- é que já sempre nos inserimos no seio do tempo. O tempo indica que ao Dasein é dada a possibilidade de ser o seu próprio tempo. $\mathrm{O}$ que está sendo dito com isso não é que ao experimentar, pela indeterminação de sua essência, seu caráter de poder-ser, o Dasein passa a criar para si um tempo particular, como se seu dia a partir de então deixasse de ter vinte e quatro horas. O que se conquista na propriedade é a dimensão fundamental do tempo, aquilo de que tempo é evidentemente tempo, ou seja, tempo 
existencial do si-mesmo e da sua busca por sentido. Com isso, realizando que todo cuidado diz respeito a uma estrutura temporal que exige por meio dela uma lida do Dasein com sua própria existência, esse fato revela que pertencemos necessariamente ao âmbito temporal e por isso também, epocal.

É justamente nesse ponto que é preciso compreender bem a noção de cuidado em Heidegger e no seu projeto de pensamento. A lida do Dasein com os entes que lhe vêm ao encontro revela o caráter temporal desse mesmo ente que se configura como abertura de mundo. Não apenas o caráter temporal do Dasein, mas também o pertencimento de todo ente a uma determinada semântica histórica. O projeto de uma ontologia fundamental estabelece tal espinha dorsal no interior de Ser e tempo: do Dasein à abertura de mundo, da abertura de mundo ao cuidado e do cuidado à semântica sedimentada do mundo histórico. Essa trajetória do texto indica justamente que o Dasein abre sua facticidade cotidiana como uma sedimentação de elementos legados pela tradição, a partir da qual esse Dasein mesmo necessariamente se estabelece. Heidegger consegue vincular, então, facticidade e tradição por meio dos momentos constitutivos do Dasein e pensar, a partir disso, a rearticulação de tais elementos da ontologia tradicional por meio da existência singular. Não cabe aqui desenvolver esses elementos a fundo, mas apenas indicar que essa é a estrutura básica de Ser e tempo: Heidegger vincula o Dasein a determinada hermenêutica fática que oferece elementos da tradição, cabendo ao movimento de transformação do Dasein a rearticulação dos elementos dessa mesma tradição por meio da pergunta pelo sentido fundamental do ser, se experimentado de forma originária.

Em suma, é preciso sempre compreender a noção de cuidado articulada com o projeto da ontologia fundamental. Heidegger centraliza a noção de cuidado para vincular a analítica do Dasein aos sentidos e significados sedimentados pelo cotidiano. Ser e tempo nasce da necessidade de uma retomada da pergunta ontológica. O intuito fundamental da obra de 1927 é o de reconstruir e dar voz a uma retomada da ontologia que destrua a calcificação da ontologia tradicional, dando nova vida ao que caducou. Como foi visto, nesse processo de fomento de uma renovação ontológica, três instâncias se revelam como igualmente fundamentais: a própria destruição da ontologia tradicional, a hermenêutica da facticidade e a analítica existencial. Esses três elementos compõem os passos necessários de Ser e tempo na sua tentativa de construção de uma ontologia fundamental. Tendo isso em vista, a analítica existencial surge como primeiro passo a ser dado e Heidegger, se utilizando de um precedente fenomenológico, imprime a descrição dos momentos fenomenológicos do Dasein. Os momentos que compõem a existência recebem o nome de estruturas ontológicas, isto é, são 
condições de possibilidade para que esse ente que somos se dê enquanto tal. Relembrando, a cadeia de momentos que se estabelece no texto é a seguinte: o copertencimento entre Dasein e mundo leva o Dasein a ter de se relacionar com os entes que lhe são abertos por esse aí mesmo; esse ter de lidar com os entes insere o Dasein numa necessária dinâmica de cuidado, o ter de lidar com os entes revela o caráter temporal desse ente. É assim na medida em que o Dasein já sempre precisou inserir-se como lida ekstaticamente interessada com os itens do real, revelando que cada elemento desse real convoca a determinada ação a ele correspondente e se insere como elemento de uma semântica histórica específica. Esse fato indica que pré-ontologicamente, ao lidar com os entes, o ser-aí já sempre compreendeu e assimilou os sentidos e significados dos elementos que compõem sua vida cotidiana. Esse é o elo importante que enlaça a analítica do Dasein à hermenêutica da facticidade de início como uma mera reprodução dos sentidos e significados tradicionais, perfazendo dessa forma, também, uma união com a história da ontologia tradicional. Cuidado, então, tem a ver com o imperativo fático da existência em ter de lidar incessantemente com o seu existir, de modo que seja possível a partir daí implodir a estabilização dos sentidos e significados cotidianos, dando passagem, às últimas consequências, à destruição da ontologia tradicional por meio da quebra do caráter óbvio da existência cotidiana.

\section{Os Impasses entre Heidegger e Binswanger}

Os desentendimentos entre Binswanger e Heidegger se iniciam na década de 1940, após a publicação da obra Grundformen und Erkenntnis menschlichen Daseins (Binswanger, 1942/1964). Nesse tratado, o psiquiatra tenta buscar um fundamento para sua prática, baseando-se na analítica existencial exposta em Ser e Tempo, porém acrescentando desenvolvimentos próprios, enfatizando o papel do amor (Liebe) em complemento ao cuidado (Sorge); e da transcendência, exposta na noção de ser-para-além-do-mundo (Über-die-Welthinaus-sein), em complemento ao ser-no-mundo (In-der-Welt-sein) heideggeriano.

Em uma troca de correspondências datadas de 1947 (Binswanger, 2019, p. 214-219), Heidegger realizou pela primeira vez uma exposição de sua opinião sobre os desenvolvimentos de Binswanger. Em uma primeira carta, o filósofo elogia o ímpeto do psiquiatra, caracterizando sua empreitada até então como uma verdadeira "virada no ser, na qual a essência e o domínio da técnica e, com isso, a essência da ciência moderna estão em jogo" (p. 215), ao que Binswanger responde que Husserl teria sido o responsável por afastá-lo do naturalismo, enquanto Heidegger seria o responsável por afastá-lo do idealismo. A tréplica 
de Heidegger permanece elogiosa, e traz alguns pensamentos breves sobre o papel da poesia e da linguagem como morada do ser.

No entanto, em uma carta de 1962 escrita por Binswanger e destinada a Heidegger observamos uma brusca mudança de tratamento e uma tensão que não estava presente anteriormente. Nessa carta (Binswanger, 2019, p. 222), o psiquiatra se desculpa e dirige ao filósofo uma cópia do prefácio da terceira edição do tratado Grundformen, no qual admite ter cometido equívocos no entendimento da analítica existencial e se encaminhado rumo ao que ele mesmo nomeia como uma fenomenologia antropológica. Mas o que teria mudado em quinze anos? Quais teriam sido os equívocos e como teriam sido notados?

Na terceira carta de 1947 (Binswanger, 2019, p. 218-219), Heidegger apontara sutilmente uma questão a ser pensada por Binswanger. Nas palavras do filósofo:

(...) o "ser-no-mundo" deve denominar a essência do ser do homem e responder com um dizer, que retoma uma vez mais o que precisa ("ser") nomeado. Aqui há mais do que um "círculo" que foi apenas suficientemente levado em conta. Menciono esse caso apenas para indicar que é bom no pensar retornar frequentemente como aqueles que acabaram de chegar, para lá onde o caminho já se conduziu uma vez. (Binswanger, 2019, pp. 219)

Parece-nos, de início, uma proposição abstrata e de difícil entendimento, pois em que consistiria tal círculo mencionado? Em que momento ele aparece na obra de Binswanger? Em verdade, não se trata de um questionamento simples, tanto é que a resposta só viria após sete anos, em uma carta de Binswanger datada de 1954 (Binswanger, 2019, p. 220-221). Nessa carta o psiquiatra admite que há mais além do círculo, e que tal questão não saiu de sua cabeça desde então. Diz, ainda, em uma nota em separado, que após a leitura da conferência de Heidegger intitulada $O$ que significa pensar? ele mesmo foi levado a um espanto filosófico ao se dar conta de que "toda doutrina do ser já é em si uma doutrina da essência do homem”. (Binswanger, 2019, p. 221)

Ainda assim, torna-se difícil perceber o que está de fato em questão. Isso ocorre porque a chave de entendimento para esse e outros questionamentos não se encontra nas cartas entre Heidegger e Binswanger, mas no material organizado por Medard Boss e publicado sob o nome de Seminários de Zollikon (Heidegger, 2009a), contendo a transcrição de aulas, o conteúdo de cartas e a transcrição de diálogos entre Boss e Heidegger. Cabe salientar que nesse contexto, tendo Boss se aproximado também do pensamento tardio de 
Heidegger, e tendo ambos uma relação mais próxima, o filósofo parece ter se sentido mais livre para tecer críticas a Binswanger.

No conjunto das transcrições de aulas, observamos apenas uma crítica dirigida a Binswanger e sua daseinsanálise, em parte das aulas de 23 e 26 de novembro de 1965 (Heidegger, 2009a, p. 151-159). Nessa transcrição, Heidegger tenta responder a três críticas dirigidas à daseinsanálise e à Analítica do Dasein: falta de cientificidade, falta de objetividade e ser hostil ao conceito. Para isso, diferencia a Analítica do Dasein, desenvolvida em Ser e Tempo, da daseinsanálise psiquiátrica de Binswanger, tecendo também algumas críticas à versão psiquiátrica. Heidegger situa a daseinsanálise como uma investigação ôntica, em contraposição e complemento à sua investigação da analítica do Dasein, de caráter ontológico. Além disso, expõe a etimologia dos termos análise e analítica como forma de elucidar suas perspectivas. Com relação aos desenvolvimentos de Binswanger, acusa-o de confundir análise e analítica, perdendo de vista a diferença entre o plano ôntico e o ontológico.

Ainda nessa crítica, Heidegger aponta que somente a partir da confusão empreendida por Binswanger é que seria possível complementar o cuidado (Sorge) com o amor (Liebe). Isso porque o amor seria, nesse contexto, um fenômeno ôntico que surge a partir do existencial cuidado. Ou seja, o cuidado é a condição de possibilidade para que o amor se configure no plano ôntico. Além disso, Binswanger teria perdido de vista em seus desenvolvimentos o existencial mais central da analítica: a compreensão. Com isso, acabaria por negligenciar a abertura ao ser e permanecer em uma perspectiva subjetivista na qual também estaria Husserl.

Nos diálogos de 1965 (Heidegger, 2009a) a crítica se desdobra em novas formulações e maiores detalhes. Em uma conversa de 8 de março Heidegger aponta, além da apropriação equivocada do existencial cuidado (Sorge), também um desdobramento equivocado da noção de transcendência, de modo que Binswanger não teria percebido que para Heidegger, em sua analítica existencial, a transcendência é um caractere fundamental do Dasein, já que cabe a todo Dasein decidir-se, decidir seu próprio ser em meio às condições nas quais está posto. Daí deriva que ser-no-mundo (In-der-Welt-sein) não é condição de possibilidade para o Dasein, mas justamente o inverso. E a transcendência não estaria relacionada à projeção de um mundo pelo Dasein, já que não se trata de um sujeito ou consciência, de modo que o ser-para-alémdo-mundo (Über-die-Welt-hinaus-sein) de Binswanger pressuporia vontade ou, ainda, desejo, tal como nomeado pela psicanálise.

Heidegger diz: 
"O Dasein transcende", isto é, como estar fora do aí enquanto clareira do ser ele deixa acontecer "mundo". Mas ele não sai inicialmente de si e para fora na direção do outro. Ele é, como ser do "aî", o lugar de tudo que vem ao encontro. Dasein não é "sujeito". Não há mais pergunta pela subjetividade. A transcendência não é "a estrutura da subjetividade", mas sim sua eliminação! (Heidegger, 2009a, pp. 230)

Heidegger (2009a) ainda esclarece o que entende por transcendência logo em seguida, compreendida como pre-sença do pre-sente. Ou seja, não como propriedade de um sujeito em relação a um objeto, mas como ser, como relação com o ser. Uma formulação que invalida a noção de transcendência tal como entendida por Binswanger. Já no diálogo de 30 de novembro Heidegger retorna à problemática da análise e da analítica e aponta:

A "Daseinsanalyse" de Binswanger, de acordo com seu caráter fundamental, é uma interpretação ôntica, isto é, uma interpretação existenciária do respectivo Dasein factual. A relação entre interpretação ôntica e ontologia é, historicamente, sempre correlativa, uma vez que se descobrem novos existenciais a partir da experiência ôntica. (Heidegger, 2009a, pp. 246)

É preciso pensar, ainda, o lugar e os limites das disciplinas científicas e da filosofia. Lembremo-nos do questionamento feito por Binswanger a Heidegger em 1955: "Até que ponto o doente mental também está aberto para o ser e se mantém no ser?" (Binswanger, 2019, p. 169). Ou, ainda, da frase escrita em uma carta de 1954: “Tal solução, porém, só pode ser buscada pelo filósofo; eu mesmo nunca me considerei um filósofo" (Binswanger, 2019, p. 220, grifo nosso). Até onde deve ir o questionamento filosófico, e em que ponto se inicia o questionamento psiquiátrico ou psicológico?

\section{Conclusão}

A complexa relação de proximidade-distância entre os pensamentos de Binswanger e Heidegger parece passar fundamentalmente pela questão de produzir, ou não, por meio da analítica do Dasein, algum tipo de ciência ôntica. Binswanger, na medida em que é psiquiatra e tem a finalidade de elaboração de um proceder clínico, busca em Ser e tempo a fonte para o desenvolvimento da daseinsanálise como um método psiquiátrico e um saber antropológico. 
No entanto, como se sabe, a postura heideggeriana sempre fora a de manter distância em relação à toda tentativa de captura da ontologia fundamental na direção da construção de alguma ciência ôntica que pudesse ser sua porta voz. Nesse sentido indica Stein:

Nessa maneira de tratar aqueles que levam em consideração a sua obra, quase temos a impressão de que realmente o filósofo [Heidegger] quer ser o único intérprete de si mesmo, e parece inclinar-se fortemente para uma recusa total de aproximação da estrutura analítico-existencial de uma estrutura antropológica que possa ser mediadora para uma compreensão psiquiátrica de afecções psíquicas do ser humano. Se esse é o caso, então, continuem os cientistas, e os perguntadores pela condição humana, a acertar e errar por conta própria, sem terem licença para se aproximar do filósofo. (Stein, 2012, pp. 123)

A distância forçada por Heidegger em relação à daseinsanálise de Binswanger lembra a barreira que aquele filósofo constrói em relação à hermenêutica diltheiana - que claramente posiciona a psicologia como ciência fundamental. Isso fica claro quando Dilthey (2010) afirma que "o resultado para a exposição [de introdução às ciências humanas] é o seguinte: a mais simples descoberta que a análise da realidade efetiva histórico-social consegue alcançar se encontra somente na psicologia” (p. 47). Ao fazer essa indicação, Dilthey procede de modo a tornar central uma ciência ôntica - no caso a psicologia - na tarefa de pensar o jogo hermenêutico-histórico da vida humana. Somente por meio da psicologia que esse conhecimento seria possível. Claramente, o modus operandi heideggeriano nesse caso é o de rechaçar tal posicionamento uma vez que nenhuma ciência ôntica pode ultrapassar a ontologia fundamental no que se refere ao seu aspecto, obviamente, fundamental. Heidegger diz:

Dilthey permanece preso ao positivismo e não compreende as condições que precisa satisfazer para poder colocar aquilo pelo que pergunta como um problema real. Pois precisamente, e até mesmo, a sua importante descoberta, a historicidade da vida, permanece no fundo incompreendida porque não é concebida em termos ontológicos. (Heidegger, 2009b, pp. 375)

Nesse ponto, a daseinsanálise binswangeriana, pelo mesmo prisma da crítica heideggeriana, estaria um passo além da hermenêutica de Dilthey, pois leva em conta os termos ontológicos abertos por Ser e tempo. No entanto, reproduzindo a lógica do trecho 
acima, ainda estaria presa à construção de algum saber daseinsanalítico positivo, gerando com isso algum saber antropológico. Justamente nesse ponto é possível compreender a crítica específica em relação à Binswanger presente nos Seminários de Zollikon (Heidegger, 2009a) em três aspectos importantes. O primeiro deles está presente nos diálogos com Medard Boss, em particular o do dia 08 de março de 1965. Lá Heidegger indica que o Dasein binswangeriano é o Dasein de Ser e tempo mutilado, pois vinculado a um Dasein em específico e isolado - o da clínica psiquiátrica. Dessa forma, somente em seguida a tal isolamento, tal Dasein mutilado necessitaria de um acesso por meio do amor como forma de compreender o cuidado de forma antropológica, no sentido de uma produção positiva de conteúdo sobre o sujeito em questão. Heidegger (2009a) reconhece com isso uma recaída na noção de sujeito apartado do mundo, que poderia ser separado do aí e pensado isoladamente. Para Heidegger tal separação traz a necessidade do cuidado através da tonalidade do amor, como proceder que rompe esse isolamento. Além disso Binswanger recairia, como dito acima, na tentativa de encerrar a ontologia fundamental - em seu caráter nulo de conteúdo instrumental, já que balizado na diferença do ser - em alguma ciência ôntica e regional, cujo correto proceder seria o cuidado pelo amor. Desta forma, a crítica de Heidegger a Binswanger pode ser compreendida nessas três direções específicas: o ser-aí compreendido isoladamente é uma recaída no sujeito moderno (separado do mundo e do outro), o amor acoplado ao cuidado, com pretensões ontológicas em Binswanger, não passaria de uma necessidade de acesso a esse sujeito isolado e, por fim, a daseinsanálise como ciência antropológica que tomaria o lugar da ontologia fundamental, o que por princípio seria um equívoco.

Binswanger (2019) reconhece e aceita as críticas de Heidegger na medida em que afirma que a daseinsanálise é uma ciência empírica e uma antropologia fenomenológica, resguardando a distância em relação à ontologia fundamental heideggeriana. Sua pretensão é a de uma ciência ôntica e de uma ontologia regional balizada na ontologia fundamental heideggeriana (Binswanger, 2019, p. 53-60). O ponto é que Heidegger (2009a) considera que nem isso ele atinge, pois ainda trabalha com noções do sujeito moderno e todo desenvolvimento posterior de seus achados está preso à essa base, como o cuidado - um tanto instrumentalizável - pelo amor.

Para Heidegger, a presença do outro não pode ser acoplada ao ser-aí individual como se primeiro existisse por si só o indivíduo sozinho e a companhia do outro surgisse de uma soma a esse isolamento. Pelo contrário, o Dasein sempre já trouxe consigo o outro no cerne da abertura de mundo que ele mesmo é. A existência não é isolada, pois ela surge cooriginariamente à existência do outro. Não há delay entre os homens, todos acontecem 
juntos, remetidos ao mesmo. $\mathrm{O}$ acontecimento da verdade como desvelamento unifica a experiência em torno dela e permite com isso o caráter múltiplo desse desvelar-se do mesmo. O mesmo, aqui, é justamente o fato da verdade como desvelamento. Em Introdução à filosofia, Heidegger (2009b) diz:

Assim, não podemos perder de vista que, no ser-um-com-o-outro junto ao mesmo, a mesmidade expressa uma relação essencial e, com efeito, uma relação que não se volta simplesmente para trás, na direção do ente mesmo, mas justamente se evade e se move na direção de muitos. Mas como é que isso se dá? Para nós, o ente por si subsistente junto ao qual somos é algo compartilhado. Ele é o mesmo para muitos, de modo que esses muitos se tornam um "nós". (Heidegger, 2009b, pp. 102)

O ser em Heidegger abre o caráter co-originário do nós que reserva a experiência fundamental de que se abre uma irmandade frente ao inapreensível do fundamento, o nós essencialmente plural. Nesse aspecto, tentar extrair desse caráter inapreensível alguma ciência positiva, por maior boa intenção que essa tarefa possa ter em Binswanger, recai na tentativa de produzir algum saber antropológico que conte com o inapreensível como apreensível por meio de algum conteúdo positivo a ser elaborado e descoberto - ainda que fenomenologicamente. Percebe-se, com isso, elementos do cálculo e do cômputo de expectativas frente ao que não pode acontecer nesse registro de pensamento. Por esse viés, a interpretação segundo a qual a daseinsanálise binswangeriana se estabelece como um equívoco produtivo fica mais bem traduzida caso seja pensada como um equívoco da produção, uma vez que Binswanger reproduz elementos da técnica justamente lá onde tais elementos deveriam permanecer inoperantes.

\section{Referências}

Binswanger, L. (2019). Psicoterapia e Análise Existencial: Ensaios, Conferências e Outros Documentos (M. A. Casanova, Trad.). Rio de Janeiro: Via Verita. (Obra original publicada em 1934-1948)

Binswanger, L. (1964). Grundformen und Erkenntnis menschlichen Daseins (4a ed.). Zurich:

Max Niehans. (Obra original publicada em 1942)

Dilthey, W. (2010). Introdução às ciências humanas. Rio de Janeiro: Forense Universitária.

(Obra original publicada em 1883) 
Duarte, I. B. (2019). A nostridade como aí do ser: O dasein para Binswanger. In A. M. L. C. Feijoo, \& M. B. M. F. Lessa (Orgs.), Daseinsanálise Hoje (pp. 15-48). Rio de Janeiro: IFEN.

Heidegger, M. (2012). Ontologia (hermenêutica da facticidade). Petrópolis: Vozes. (Obra original publicada em 1923)

Heidegger, M. (2010) Fenomenologia da vida religiosa. Petrópolis: Vozes: Bragança Paulista: USF. (Obra original publicada em 1918-1921)

Heidegger, M. (2009a). Seminários de Zollikon: Ensaios, Diálogos e Cartas (2a ed.). Petrópolis: Vozes. (Obra original publicada em 1989)

Heidegger, M. (2009b). Introdução à filosofia (2a ed.). São Paulo: Martins Fontes. (Obra original publicada em 1928)

Heidegger, M. (1988). Ser e tempo (3a ed.). Rio de Janeiro: Vozes. (Obra original publicada em 1927)

Hertz, M. (2013) Introdução do editor. In L. Binswanger, Sonho e existência: Ensaios e conferências 1: Escritos sobre fenomenologia e psicanálise. (M. A. Casanova, Trad.). Rio de Janeiro: Via Verita.

Husserl, E. (2007). Investigações lógicas (Vols. 1-2, P. Alves \& C. Marujão, Trad.). Lisboa: Centro de Filosofia da Universidade de Lisboa. (Obra original publicada em 1901)

Loparic, Z. (2002). Binswanger, leitor de Heidegger: Um equívoco produtivo?. Natureza humana, 4(2), 383-413. Recuperado de http://pepsic.bvsalud.org/scielo.php?script=sci_abstract\&pid=S151724302002000200006

Machado, P. R. R. (2019) Introdução. In L. Binswanger, Psicoterapia e Análise Existencial: Ensaios, Conferências e Outros Documentos (M. A. Casanova, Trad.). Rio de Janeiro: Via Verita.

Stein, E. (2012). Analítica existencial e psicanálise: Freud, Binswanger, Lacan, Boss. Ijuí: Unijuí.

\section{Endereço para correspondência}

\section{Ana Maria Lopez Calvo de Feijoo}

Rua São Francisco Xavier, 524, Maracanã, Rio de Janeiro - RJ, Brasil. CEP 20550-900

Endereço eletrônico: ana.maria.feijoo@gmail.com

\section{Marcello Furst de Freitas Accetta}

Rua São Francisco Xavier, 524, Maracanã, Rio de Janeiro - RJ, Brasil. CEP 20550-900 
Endereço eletrônico: marcelloffaccetta@gmail.com

\section{Myriam Moreira Protasio}

Rua São Francisco Xavier, 524, Maracanã, Rio de Janeiro - RJ, Brasil. CEP 20550-900

Endereço eletrônico: myprotasio@yahoo.com.br

\section{Paulo Victor Rodrigues da Costa}

Rua São Francisco Xavier, 524, Maracanã, Rio de Janeiro - RJ, Brasil. CEP 20550-900

Endereço eletrônico: pvrcosta@gmail.com

\section{Victor Portavales Silva}

Rua São Francisco Xavier, 524, Maracanã, Rio de Janeiro - RJ, Brasil. CEP 20550-900

Endereço eletrônico: victorportavales@ hotmail.com

Recebido em: 22/05/2020

Aceito em: 04/09/2020

\section{Notas}

* Psicóloga, graduada pela Faculdade de Humanidades Pedro II, mestre em Psicologia pela FGV, doutora em Psicologia pela UFRJ, pós-doutora em Psicologia e Filosofia pela UFRJ, professora da Universidade do Estado do Rio de Janeiro.

** Psicólogo formado pela Unesa, mestre em Psicologia pela UFRJ, doutorando do PPGPS da Uerj. Professor e coordenador do curso de Psicologia da Unisuam.

*** Psicóloga. Doutora e mestre em Filosofia pela Uerj. Pós-Doutorado em Psicologia no Programa de PósGraduação em Psicologia Social da Uerj. Sócia-Fundadora do IFEN.

**** Formado em Psicologia (Uerj), formado em Filosofia (UFRJ), mestre em Psicologia Social (PPGPS-Uerj), doutor em Filosofia (UFRJ).

***** Psicólogo formado pela Uerj, mestre em psicologia pelo PPGPS/Uerj, especialista em psicologia clínica pelo IFEN.

${ }^{1}$ Todas as traduções do Grundformen foram feitas por Alexander de Carvalho sob demanda dos autores.

${ }^{2}$ Aqui cabe citar os textos Ontologia, de 1923, e Fenomenologia da vida religiosa, de 1918-21, onde Heidegger esboça a noção de cuidado sem, no entanto, vincular claramente ao projeto de ontologia fundamental como em Ser e tempo.

Este artigo de revista Estudos e Pesquisas em Psicologia é licenciado sob uma Licença Creative Commons Atribuição-Não Comercial 3.0 Não Adaptada. 